\title{
Undernutrition and its association with socio-demographic, anemia and intestinal parasitic infection among pregnant women attending antenatal care at the University of Gondar Hospital, Northwest Ethiopia
}

\author{
Gemechu Kumera $^{1 *}$, Dereje Gedle ${ }^{1}$, Animut Alebel ${ }^{2}$, Fetuma Feyera ${ }^{2}$ and Setegn Eshetie ${ }^{3}$
}

\begin{abstract}
Background: Under nutrition is a worldwide public health problem affecting the well-being of millions of pregnant women in the developing world. Only limited research has been conducted on the prevalence and determinants of maternal nutritional status in Ethiopia. Particularly, data on the nutritional status of pregnant women are lacking. The aim of this study was to assess the prevalence and determinants of undernutrition among pregnant women attending antenatal care at the University of Gondar Hospital, Northwest Ethiopia.

Methods: An institution based cross-sectional study was conducted in January and February 2016. Randomly selected 409 pregnant women were included in the study. Nutritional status was estimated using mid-upper-arm circumference. Data on potential determinants of undernutrition were gathered using a structured questionnaire. The blood sample was collected to analyze hemoglobin. The stool sample was collected to identify intestinal parasitic infections. Statistical analysis was done using logistic regression. $P$-value $<0.05$ at $95 \%$ confidence interval was considered as statistically significant.

Results: The prevalence of undernutrition among pregnant women was $16.2 \%$ (95\% Cl: 12.4-20.1\%). Using a logistic regression model, factors significantly associated with the undernutrition were living in rural areas $(A O R=2.26)$, low educational status [no formal education $(A O R=2.91)$, primary education $(A O R=2.69)$ ], history of too many births $(A O R=2.55)$, anemia $(A O R=2.01)$, and intestinal parasitic infection $(A O R=2.73)$.

Conclusion: The study findings provide evidence for the public health significance of under nutrition among pregnant women in the study area. The problem must be combated through rural livelihood promotion, socioeconomic empowerment of women, sustained nutrition education and expansion of family-planning services in the area.
\end{abstract}

Keywords: Undernutrition, Pregnant women, Northwest Ethiopia

\footnotetext{
* Correspondence: gemechisfreedom@gmail.com

'Department of Public Health, College of Medicine and Health Science,

Debre Markos University, Debre Markos, Ethiopia

Full list of author information is available at the end of the article
}

(c) The Author(s). 2018 Open Access This article is distributed under the terms of the Creative Commons Attribution 4.0 International License (http://creativecommons.org/licenses/by/4.0/), which permits unrestricted use, distribution, and reproduction in any medium, provided you give appropriate credit to the original author(s) and the source, provide a link to the Creative Commons license, and indicate if changes were made. The Creative Commons Public Domain Dedication waiver (http://creativecommons.org/publicdomain/zero/1.0/) applies to the data made available in this article, unless otherwise stated. 


\section{Background}

Undernutrition and poor health from preventable causes disproportionately affect the well-being of millions of people in the developing world [1]. Maternal undernutrition is a worldwide public health problem affecting a high proportion of women in developing countries [2]. Women and young children are the most affected [3]. More than 3.5 million women and children under age five in developing countries die each year due to the underlying cause of undernutrition [4]. Women in sub-Saharan Africa, south-central and southeastern Asia are the most affected [3].

Ethiopia faces one of the world's highest rates of maternal undernutrition. The analysis of Ethiopian Demographic Health Surveys (EDHS) 2000, 2005 and 2011 data revealed 30.5, 26.9, 27\% of women in Ethiopia are undernourished respectively [5-7]. Based on recently conducted DHS country surveys, the proportion of undernourished women in sub-Saharan African countries ranges from 7 to $37 \%$, indicating that maternal undernutrition in Ethiopia is higher than the level for many African countries [8].

Maternal prenatal undernutrition has a major impact on their own health as well as their children's health. Increased perinatal and neonatal mortality, a higher risk of low birth weight and stunted babies, intrauterine growth restriction, stillbirths, and miscarriage are some of the consequences of undernutrition in women, which further undermines the human capital development of the family and society, and continues the cycle of poverty and malnutrition [9-15].

Undernutrition is a serious problem in Ethiopia. One of every four (27\%) women in Ethiopia are undernourished [7]. Although the government and nongovernmental organizations have been perpetually working to improve the nutritional status of the women, the outcome of these efforts has not yet knocked mitigating effect on the prevalence of undernutrition among women in Ethiopia.

Only limited research has been conducted on the prevalence and determinants of maternal nutritional status in Ethiopia. Particularly, data on the nutritional status of pregnant women are lacking. Information on the nutritional status and associated factors among pregnant women are needed for prioritizing, designing and initiating intervention programs aimed at improving maternal nutrition. In addition, such data can be employed in programmes that are aimed to reduce maternal and child morbidity and mortality. Thus, this study was carried out to provide information regarding the prevalence and factors associated with undernutrition during pregnancy.

\section{Methods}

\section{Study design, area and population}

An institution based cross-sectional study was conducted at the University of Gondar Hospital in January and February 2016. The University of Gondar Hospital is a tertiary-level service-rendering institution that provides health service to over 4 million people in Gondar town and surrounding area. The Gondar town lies in the average at $2000 \mathrm{~m}$ above sea level and over 370,000 population reside in this administrative town [16]. The study populations were all pregnant women in Gondar town and surrounding area who attend antenatal care (ANC) at the University of Gondar Hospital.

\section{Sample size and sampling technique}

A sample size of 409 was computed using single population proportion sample size calculation formula with inputs of $95 \%$ confidence level, $4 \%$ margin of error, $19.1 \%$ expected prevalence of undernutrition [17] and 10\% non-response rate. A systematic random sampling technique was used to select the study subjects. According to the Hospital report, on average, 35-45 pregnant women visit the ANC daily, and 1241 pregnant women have been enrolled in ANC. Since the sample size was determined as 409 , a sampling interval of 3 was used to select study participants. Of the first three pregnant women, one woman was randomly selected by using lottery method (The pregnant women is assigned to unique number (1,2 and 3), putting it on a piece of paper. The pieces of paper are placed in the container and thoroughly mixed. Then, a blind folded researcher picks a number. Number three (3) was selected.). Accordingly, every 3rd pregnant women were selected to participate in the study until the required sample size of 409 pregnant women was obtained.

\section{Data collection methods Questionnaire}

A structured and pre-tested questionnaire was used for assessing potential determinants of undernutrition. The parts of the questionnaire on dietary diversity were adopted from Food and Nutrition Technical Assistance (FANTA) indicator guideline [18]. Other parts of the questionnaire were developed by the principal investigators. The questionnaire was administered in a local language(Amharic). The English version of the questionnaire was translated into local language and back to English by an expert to ensure its consistency. The translated Amharic version (local language) was pre-tested prior to the actual survey and modifications were made accordingly. The content validity of the tool was checked against the conceptual framework of the study by relevant professionals. Reliability of the tool was checked using a test-retest method. Questions with less than 0.7 kappa or Pearson coefficient values were removed or revised. Five data collectors (three midwives and two laboratory technicians) and one supervisor were recruited. Training was given for data collectors and 
supervisor by the principal investigator to have consensus and the same understanding of what is intended to be measured by each question in the questionnaire. The data collection process was followed daily by the supervisor and principal investigator. The dietary diversity (DD) level was assessed using 24-h recall method. Respondents were asked whether they had taken any food from predefined 12 food categories on a preceding day. Accordingly, the level of Dietary Diversity Score (DDS) was computed out of 12. According to the recommendation of Food and Agriculture Organization (FAO) of the United Nations, DD was classified into low (DDS $\leq 3$ ), medium (DDS of 4 or 5), or high (DDS $\geq 6$ ) [19]. Pregnant women from all trimesters (first, second and third) were included in the study.

\section{Mid upper arm circumference (MUAC) measurement}

Mid upper arm circumference was measured halfway between the tip of the shoulder (olecranon process) and the tip of the elbow (acromion process) to the nearest $0.1 \mathrm{~cm}$. An insertion type MUAC tape that is non-elastic and non-stretchable was used to take the measurement. The measurement was taken at the mid-point on the relaxed left arm, without any clothing and with optimal tape tension (not too loose or not too tight) following the standard instructions and steps [20]. Recently published paper based on a review of evidence revealed that MUAC is a preferred anthropometric measurement during pregnancy [21] and also not affected by non-nutritional changes [22]. Undernutrition was defined as MUAC less than $22 \mathrm{~cm}$ [23].

\section{Laboratory analysis \\ Hemoglobin level determination}

Venous blood was collected from each pregnant woman, using sterile blood collection tubes following standard procedures. Hemoglobin level was determined using hematological analyzer (Cell Dyn 1800, PD, USA) machine. Anemia was defined as a hemoglobin level of less than $11.0 \mathrm{~g} / \mathrm{dl}$ during the first or third trimester or less than $10.5 \mathrm{~g} / \mathrm{dl}$ during the second trimester [24]. According to the formula recommended by Center for Disease Prevention and Control, hemoglobin values were adjusted for altitude [25].

\section{Stool specimen collection and examination}

Stool samples were collected from participants using clean, dry and leak-proof cupped plastic container following standard procedures. The stool samples were masked, coded, and processed for parasitological examination. Different stool examinations were used for efficacy in detecting parasites. These were direct wet-mount and formaldehyde-ether sedimentation method [26, 27].
The WHO guide for diagnosis of intestinal parasitosis was used as an identification reference [28].

\section{Data processing and analysis}

Data were entered using EPI-INFO version 7 software. The analysis was carried out using SPSS version 20 statistical program. Wealth index (poor, middle and rich) were computed using principal component analysis as a composite indicator of living standard. In this study, undernutrition (MUAC $<22 \mathrm{~cm}$ ) was an outcome variable. Bivariate and multivariable logistic regression analysis was used to assess the association between the dependent and independent variables and to control confounders. Independent variables significantly associated with the dependent variable in bivariate regression models were exported to multivariable regression models for adjustment. The collinearity effect was tested using the Variance Inflation Factor (VIF) for all independent variables. Model fitness was assessed using the Hosmer-Lemeshow statistic test. $P$-value $<0.05$ at $95 \%$ $\mathrm{CI}$ was considered statistically significant.

\section{Ethical cosideration}

The study was conducted in confirmation of national and international ethical guidelines for biomedical research involving human subjects. Ethical clearance was obtained from an ethical review committee of the University of Gondar. Written informed consent was obtained from each study participants prior to participation in the study after the nature of the study was fully explained to the study participants. Women who had intestinal parasites and anemia were treated accordingly. Those women identified as undernourished were referred to ANC clinicians for treatment. Nutrition education was given to all study participants. Those participants identified as undernourished were given nutritional counseling and Ready Use Therapeutic Food (RUTF) in collaboration with the clinicians working in an ART clinic at Hospital.

\section{Results}

Socio-demographic characteristics of the study participants

Table 1 summarizes socio-demographic characteristics of the study participants. Of the total 409 pregnant women, initially planned for the study, 402 were volunteered to take part in the study, with a response rate of 98.3\%. The vast majority of the respondents were Amhara in ethnicity $(94.8 \%)$ and orthodox $(88.6 \%)$ in religion. The majority of participants $(62.4 \%)$ were in the age group 25-34 years with the mean and standard deviation of $26.6( \pm 4.7)$ years. Nearly One-fourth of study subjects, 92(22.9\%) had no formal education and more than half, 221 (55.0\%) were housewives. The majority, 
Table 1 Socio-demographic characteristics of the study participants, Northwest Ethiopia, $2016(n=402)$

\begin{tabular}{|c|c|c|c|}
\hline \multicolumn{2}{|l|}{ Characteristics } & \multirow{2}{*}{$\frac{\text { Frequency }(\mathrm{n})}{120}$} & \multirow{2}{*}{$\begin{array}{l}\text { Percent (\%) } \\
29.9\end{array}$} \\
\hline Age(years) & $15-24$ & & \\
\hline & $25-34$ & 251 & 62.4 \\
\hline & $\geq 35$ & 31 & 7.7 \\
\hline \multirow[t]{2}{*}{ Residence } & Urban & 303 & 75.4 \\
\hline & Rural & 99 & 24.6 \\
\hline \multirow[t]{5}{*}{ Marital status } & Married & 386 & 96 \\
\hline & Single & 7 & 1.7 \\
\hline & Divorced & 2 & 0.5 \\
\hline & Separated & 6 & 1.5 \\
\hline & Widowed & 1 & 0.2 \\
\hline \multirow[t]{3}{*}{ Religion } & Orthodox & 356 & 88.6 \\
\hline & Muslim & 37 & 9.2 \\
\hline & Protestant & 9 & 2.2 \\
\hline \multirow[t]{4}{*}{ Ethnicity } & Amhara & 381 & 94.8 \\
\hline & Tigre & 15 & 3.7 \\
\hline & Oromo & 2 & 0.5 \\
\hline & Other & 4 & 1.0 \\
\hline \multirow[t]{4}{*}{ Educational status } & No formal education & 92 & 22.9 \\
\hline & Primary education & 84 & 20.9 \\
\hline & High school education & 112 & 27.9 \\
\hline & Certificate and above & 114 & 28.4 \\
\hline \multirow[t]{6}{*}{ Occupation } & House wife & 221 & 55.0 \\
\hline & Farmer & 13 & 3.2 \\
\hline & Merchant & 51 & 12.7 \\
\hline & Government employee & 94 & 23.4 \\
\hline & Daily laborer & 11 & 2.7 \\
\hline & Student & 12 & 3.0 \\
\hline \multirow[t]{3}{*}{ Family size } & $\leq 3$ & 285 & 70.9 \\
\hline & $4-6$ & 90 & 22.4 \\
\hline & $>6$ & 27 & 6.7 \\
\hline \multirow[t]{3}{*}{ Wealth Index } & Low & 134 & 33.3 \\
\hline & Middle & 134 & 33.3 \\
\hline & High & 134 & 33.3 \\
\hline
\end{tabular}

$303(75.4 \%)$, of the respondents, were urban dwellers. The average household size was $3.2( \pm 1.6)$. The median monthly household income was 2000 Ethiopian birr.

\section{Environmental and sanitation factors}

Table 2 summarizes environmental and sanitation characteristics of the study participants. Source of drinking water for the greater number, 368(91.5\%) of study subjects was tap water. The majority of study participants, 383(95.3\%) had toilet facilities. The large proportion of participants, 283(73.9\%) use pit latrine.
Table 2 Environmental and sanitation characteristics of pregnant women attending antenatal care, Northwest Ethiopia, 2016

\begin{tabular}{llll}
\hline Characteristics & & Frequency (n) & Percent (\%) \\
\hline Source of drinking water & Tab & 368 & 91.5 \\
& Well & 11 & 2.7 \\
& Spring & 23 & 5.7 \\
Possession of toilet facility & Yes & 383 & 95.3 \\
& No & 19 & 4.7 \\
Types of latrine & Pit latrine & 283 & 73.9 \\
& Water flush & 97 & 25.3 \\
& Public & 3 & 0.8 \\
\hline
\end{tabular}

\section{Reproductive health factors}

Table 3 summarizes reproductive health factors of study participants. More than half, 224 (55.7\%) of the participants were in the third trimester, 117(29.1\%) in the second and $61(15.2 \%)$ in the first trimester. The results revealed a greater majority of the participants, 198(49.3\%) had a first pregnancy at a time of data collection. In $33(8.2 \%)$ of the study participants, the birth interval was less than the recommended 24 months. The mean parity was $1.1( \pm 1.6)$, ranging between 0 and 7 pregnancies. The mean MUAC for nulliparas was 24.7 $(+/-2.6) \mathrm{cm}$. The corresponding value for parity categories of $1-3$ and 4 or more was $25.2(+/-3.1) \mathrm{cm}$ and $23.5(+/-2.8) \mathrm{cm}$, respectively.

\section{Dietary intakes of the study participants}

Table 4 summarizes dietary intakes of the study participants. The vast majority of the study subjects consumed cereal-based foods (made of teff) (Fig. 1). The commonly and frequently consumed foods were a starchy staple, $100 \%$ and legumes, 273(67.9\%). Only one-fourth, $86(21.4 \%)$ of study subjects were consumed vitamin A rich fruits and vegetables in the reference period. Two hundred forty-six, (61.2\%) of the study participants

Table 3 Reproductive health factors among pregnant women attending antenatal care, Northwest Ethiopia, 2016

\begin{tabular}{llll}
\hline Characteristics & & Frequency (n) & Percent (\%) \\
\hline Trimester of pregnancy & First & 61 & 15.2 \\
& Second & 117 & 29.1 \\
& Third & 224 & 55.7 \\
& 0 & 198 & 49.3 \\
Parity & $1-3$ & 155 & 38.6 \\
& $\geq 4$ & 49 & 12.2 \\
& $0($ No birth) & 198 & 49.3 \\
Birth interval & $<2$ yr & 33 & 8.2 \\
& $\geq 2$ yr & 171 & 42.5 \\
\hline
\end{tabular}


Table 4 Dietary intakes of pregnant women attending antenatal care, Northwest Ethiopia, 2016

\begin{tabular}{|c|c|c|c|}
\hline Characteristics & & Frequency (n) & Percent $(\%$ \\
\hline \multirow[t]{3}{*}{ Number of meals/day } & $<3$ & 46 & 11.4 \\
\hline & 3 & 282 & 70.1 \\
\hline & $>3$ & 74 & 18.4 \\
\hline \multirow[t]{3}{*}{ Family food source } & Grow their own & 70 & 17.4 \\
\hline & Buy/purchase & 330 & 82.1 \\
\hline & Subsidies/food aid & 2 & 0.5 \\
\hline \multirow[t]{3}{*}{ Dietary diversity } & Low & 267 & 66.4 \\
\hline & Medium & 123 & 30.6 \\
\hline & High & 12 & 3.0 \\
\hline \multirow[t]{2}{*}{ Home gardening } & Yes & 31 & 7.7 \\
\hline & No & 371 & 92.3 \\
\hline \multirow[t]{2}{*}{ Animal food source } & Yes & 128 & 31.8 \\
\hline & No & 274 & 68.2 \\
\hline \multirow[t]{2}{*}{ Coffee intake } & Yes & 246 & 61.2 \\
\hline & No & 156 & 38.8 \\
\hline \multirow[t]{2}{*}{ Number of cup of coffee per day } & $\leq 3$ & 190 & 77.2 \\
\hline & $>3$ & 56 & 22.8 \\
\hline
\end{tabular}

reported that they consumed coffee. A small proportion, $128(31.8 \%)$ of study participants reported that they consumed a diet of animal origin prior to the survey. Among animal products, flesh meat was consumed by 94 (23.4\%) of the study subjects, whereas egg, milk and milk products and organ meat were consumed by 20 (5\%), $25(6.2 \%)$ and $2(0.5 \%)$, respectively. The mean DDS was $3.33( \pm 0.77)$, ranging between 1 and 7 . The majority of study participants, 267 (66.4\%) had low DDS ( $\leq 3$ food groups). The meal frequency was three times a day for the majority of the study participants $282(70.1 \%)$.
Anemia, HIV and diarrhea among the study participants Of all study participants, 17(4.2\%) were positive for HIV. Among 21 study participants who were positive for HIV, 6(28.6\%) were undernourished. The mean MUAC for HIV positive and negative were $23.1( \pm 3.8)$ and $24.8( \pm 2.8)$ $\mathrm{cm}$, respectively. A small proportion, $26(6.5 \%)$ of the pregnant women had diarrhea; of whom nearly one-fourth, $6(23.1 \%)$ were undernourished. Overall, the prevalence of anemia was $132(32.8 \%)$, and was more evident in undernourished pregnant women $(25 \%)$ than in normal pregnant women $(M U A C \geq 22 \mathrm{~cm})$.

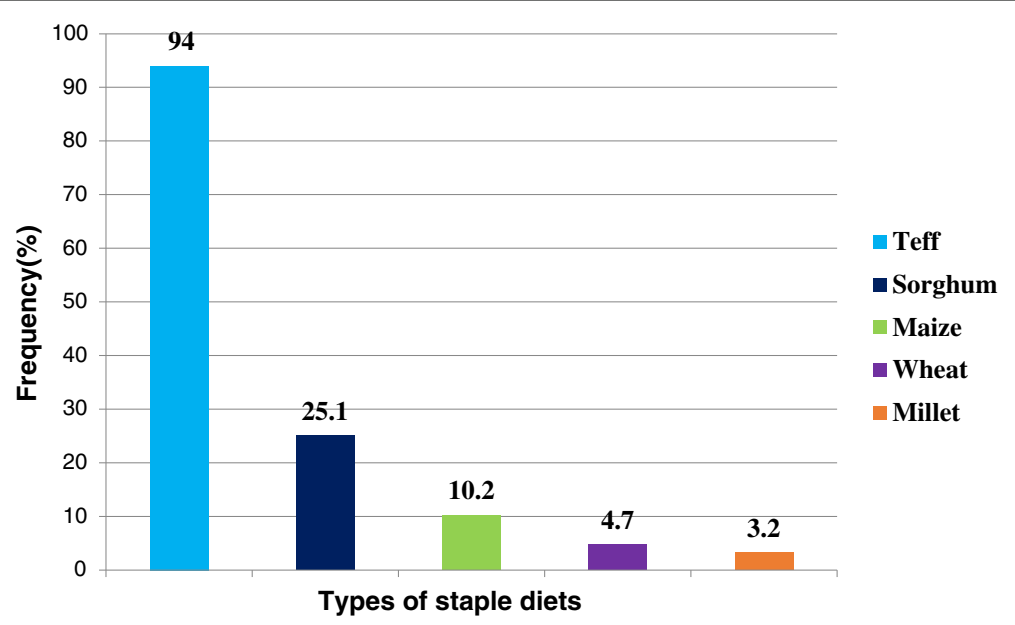

Fig. 1 Staple diets of pregnant women attending antenatal care, Northwest Ethiopia, 2016 


\section{Prevalence and type of intestinal parasites among the study participants}

Figure 2 summarizes prevalence and type of intestinal parasitic infection among the study participants. One hundred twenty-six, (31.3\%) of study participants were infected with one or more intestinal parasites. Of whom, 35(27.8\%) were undernourished. The most common single and mixed parasites observed were Entamoeba histolytica 48(38.1\%) and Ascaris lumbricoides 31(24.6\%). Intestinal parasitic infection tends increase among rural dwellers and pregnant women who used other sources of drinking water other than tap water. Of 99 rural dwellers pregnant women, 41(41.4\%) were infected with one or more intestinal parasites. Among 11 pregnant women who consumed well water, $7(63.6 \%)$ were infected with one or more intestinal parasites. Similarly, among 23 pregnant women who consumed spring water, 12(52.2\%) were infected with one or more intestinal parasites.

\section{Prevalence of under nutrition}

Undernutrition (MUAC $<22 \mathrm{~cm}$ ) was observed in 65 of 402 pregnant women studied, yielding a prevalence of 16.2\% (95\% CI: $12.4-20.1 \%)$. The mean MUAC $( \pm$ SD) of the study participants was $24.8 \mathrm{~cm}( \pm 2.9)$. The value ranged from 18 to $37 \mathrm{~cm}$. The prevalence of undernutrition during the first, second and third trimesters were, $14.8,16.2$ and $16.5 \%$, respectively. The mean MUAC $( \pm S D)$ for the first, second and third trimesters were, $24.8( \pm 3.2)$, $24.8( \pm 2.8)$ and $24.7( \pm 2.7) \mathrm{g} / \mathrm{dl}$, respectively.

\section{Factors associated with undernutrition}

Table 5 summarizes factors associated with undernutrition among pregnant women. A multivariable analysis in a form of logistic regression was employed to identify the risk factors of undernutrition among pregnant women. The analyses rest on two outcomes of nutritional status of pregnant women: whether they are undernourished (MUAC $<22 \mathrm{~cm}$ ) or not $(M U A C \geq 22 \mathrm{~cm}$ ). In the bivariate analysis, undernutrition was significantly associated with age, residence, wealth index, educational status, source of drinking water, parity, animal source food, HIV, anemia and intestinal parasite. The multivariable logistic regression analysis revealed that residence, maternal educational status, parity, anemia and intestinal parasite were predictors of undernutrition.

Place of residence was significantly associated with nutritional status of pregnant women $(P=0.03)$. The risk of undernutrition was two times, $[\mathrm{AOR}=2.26$; 95\% CI $(1.06,4.81)]$ higher among rural pregnant women than their urban counterparts.

The study also witnessed significant association between educational level and maternal nutritional status. The risk of undernutrition for pregnant women with no formal education and primary education was 2.91 and 2.69 times higher, respectively as compared to pregnant women with higher education (certificate and above) $[\mathrm{AOR}=2.91 ; 95 \% \mathrm{CI}(1.11,7.56)], \quad[\mathrm{AOR}=2.69$; $95 \%$ CI $(1.09,6.64)]$.

Significant associations were also observed between nutritional status and parity. The risk of undernutrition for pregnant women with grand multiparas was two and half times higher as compared to pregnant women with no parity $[\mathrm{AOR}=2.55 ; 95 \% \quad(1.04$, 6.26)].

Anemia was found to be significantly associated with undernutrition. Pregnant women who were anemic were

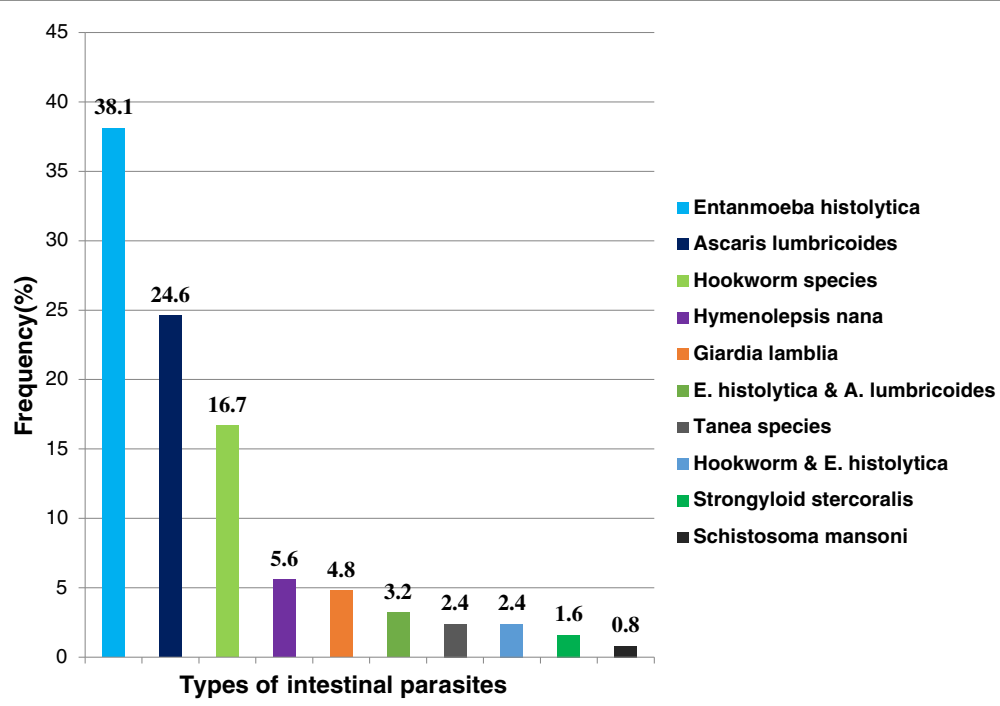

Fig. 2 Prevalence and types of intestinal parasites among pregnant women attending antenatal care, Northwest Ethiopia, 2016 
Table 5 Factors associated with the undernutrition among pregnant women

\begin{tabular}{|c|c|c|c|c|c|}
\hline \multirow[t]{2}{*}{ Predictors } & \multicolumn{2}{|c|}{ Under nutrition } & \multirow[t]{2}{*}{ COR $(95 \% \mathrm{Cl})$} & \multirow[t]{2}{*}{ AOR $(95 \% \mathrm{Cl})$} & \multirow{2}{*}{$\begin{array}{l}P \text { - } \\
\text { values }\end{array}$} \\
\hline & Yes & No & & & \\
\hline \multicolumn{6}{|l|}{ Age } \\
\hline $15-24$ & 34 & 86 & $2.36(1.01,5.53)$ & & \\
\hline $25-34$ & 28 & 223 & $2.17(0.87,5.44)$ & & \\
\hline$\geq 35$ & 3 & 28 & 1 & & \\
\hline \multicolumn{6}{|l|}{ Residence } \\
\hline Rural & 32 & 67 & $3.91(2.24,6.81)$ & $2.26(1.06,4.81)$ & $0.03^{*}$ \\
\hline Urban & 33 & 270 & 1 & 1 & \\
\hline \multicolumn{6}{|l|}{ Wealth index } \\
\hline Low & 36 & 98 & $4.54(2.13,9.70)$ & & \\
\hline Middle & 19 & 115 & $2.05(1.12,3.75)$ & & \\
\hline High & 11 & 123 & 1 & & \\
\hline \multicolumn{6}{|l|}{ Educational status } \\
\hline No formal education & 31 & 61 & $5.18(2.37,11.31)$ & $2.91(1.11,7.56)$ & $0.02 *$ \\
\hline Primary education & 12 & 72 & $4.32(2.06,9.03)$ & $2.69(1.09,6.64)$ & $0.03 *$ \\
\hline Secondary education & 10 & 102 & $3.04(1.44,6.44)$ & & \\
\hline Certificate and above & 12 & 102 & 1 & 1 & \\
\hline \multicolumn{6}{|l|}{ Source of drinking water } \\
\hline Spring & 8 & 15 & $2.54(1.00,6.47)$ & & \\
\hline Well & 3 & 8 & $2.16(0.86,5.48)$ & & \\
\hline Tab & 54 & 314 & 1 & & \\
\hline \multicolumn{6}{|l|}{ Parity } \\
\hline No birth & 23 & 175 & 1 & & \\
\hline $1-3$ & 24 & 131 & $3.63(1.76,7.51)$ & & \\
\hline$\geq 4$ & 19 & 30 & $4.82(2.34,9.91)$ & $2.55(1.04,6.26)$ & $0.04^{*}$ \\
\hline \multicolumn{6}{|l|}{ Animal source food } \\
\hline Yes & 13 & 115 & 1 & & \\
\hline No & 52 & 222 & $2.07(1.08,3.96)$ & & \\
\hline \multicolumn{6}{|l|}{ HIV } \\
\hline No & 60 & 325 & 1 & & \\
\hline Yes & 5 & 12 & $2.38(1.01,5.95)$ & & \\
\hline \multicolumn{6}{|l|}{ Anemia } \\
\hline No & 32 & 238 & 1 & 1 & \\
\hline Yes & 33 & 99 & $2.48(1.45,4.25)$ & $2.01(1.16,3.79)$ & $0.01 * *$ \\
\hline \multicolumn{6}{|l|}{ Intestinal parasite } \\
\hline Absent & 30 & 246 & 1 & 1 & \\
\hline Present & 35 & 91 & $3.15(1.83,5.43)$ & $2.73(1.48,5.03)$ & $0.001 * *$ \\
\hline
\end{tabular}

${ }^{\circ} P$-value is significant at $<0.05,{ }^{* *} P$-value is significant at $\leq 0.01$

two times more likely to be undernourished than those with normal hemoglobin level $[\mathrm{AOR}=2.01 ; 95 \%(1.16$, 3.79)].

The intestinal parasite was also found to be significantly associated with undernutrition. Pregnant women who had one or more intestinal parasitic infection were three times more likely to be malnourished as compared to those who had no intestinal parasitic infection $[\mathrm{AOR}=2.73$; 95\% CI $(1.48,5.03)]$.

In this study, nutritional status did not show any statistical association with regard to dietary diversity, family size, occupation, latrine availability, number of meals per 
day, coffee intake, staple diets, home gardening and family food source.

\section{Discussion}

This study assessed the prevalence and determinants of undernutrition among pregnant women attending antenatal care. The current study witnessed the public health significance of undernutrition in the study area. Findings of the study showed that, $16.2 \%$ of pregnant women were undernourished. In Ethiopia, few studies determined the prevalence of undernutrition in pregnant women and came up with figures 9.2\% [29], 19.1\% [17], $31.4 \%$ [30] and 34.0\% [31]. The studies consistently witnessed the public health significance of undernutrition in the country. The current study showed that prevalence of undernutrition among pregnant in the country is decreasing as compared to earlier studies. The probable reason for this variation could be the interventions on nutrition, maternal health and other women empowering programs by the government and other non-governmental organizations in the country. Moreover, the variation may be due to geographical variation, smaller land holding, the recurrent food insecurity and the seasonal difference in data collection. Further, the prevalence may have overestimated in earlier studies as only adolescent pregnant women were included in the study.

Women living in rural areas are more undernourished than their urban counterparts. Similar results have been reported from earlier studies $[3,6,32,33]$. The disparity may be due to less developed infrastructures, low nutritional awareness, low access to health care, safe water, and sanitation facilities, traditional ways of farming as only means of surviving and cultural and religious influences in rural areas. In addition, lower nutritional status among rural pregnant women could be explained partly by the fact that in rural areas women are more vulnerable to early marriage and childbearing than women in urban areas [6]. Hence, in addition to their own health needs, they need an adequate dietary intake for pregnancy and child growth. Further, the higher levels of labor or workload among rural pregnant women may contribute to poor nutritional status among pregnant women in rural areas, as overexertion is a predisposing factor to maternal nutritional depletion [34].

The study findings indicate a negative relationship between the educational status of the pregnant women and undernutrition, with decreasing educational levels from certificate and above to no formal education, the level of undernutrition tends to increase. Previous studies also have documented similar findings [30-32, 35]. The probable reason could be pregnant women who are literate may have more exposure to media, which influence their behaviour in matters related to their own feeding and health [36]. Unawareness of illiterate women about their own health and nutritional status could be another reason associated with their poor nutritional status. Moreover, the low educational level of women could be associated with little or no decision-making power in the household about food distribution, purchase of household consumption items and financial issues which may contribute to their low nutritional status. However, in a study conducted in Iran, there was no statistically significant association between pregnant women's education level and nutritional status [37]. The variation can be due to the difference in socioeconomic status and nutritional care prior to and during pregnancy.

Another finding that affects pregnant women's nutritional status is parity. The odds of undernutrition were observed to rise as parity advances. Previous studies also reported the same $[29,31,32]$. The study witnessed the deleterious effect of too many births on nutritional status. The finding is consistent with the knowledge that repeated reproductive cycles deplete maternal nutrition store. Moreover, higher-level parity obligates women to take care of their children rather than protecting their own health and nutritional status, given limited household resources.

The current study finding witnessed a significant positive association between anemia and undernutrition. The proportion of undernutrition was significantly more among anemic pregnant women compared to normal hemoglobin level pregnant women. This finding is in line with studies conducted in Ethiopia [38], Kenya [39] and India [40], which indicated that the risk of anemia tends to increase among undernourished pregnant women. This might be due to the fact that undernourished pregnant women have a higher risk of being deficient in micronutrients and therefore more likely to be anemic. As the study is cross-sectional, it is not viable to exclude "the chicken or the egg" causality dilemma. However, as protein is known to take part in multiple metabolic pathways, it might have a causal role in anemia. This relation between undernutrition and anemia might be due alterations in spleen and bone marrow erythropoiesis, reduction in reticulocyte as a result of a protein-energy deficiency in undernourished pregnant women [41].

In the present study, intestinal parasitic infection was found to be one of the determinant predictors of risk of undernutrition. Pregnant women who had one or more intestinal parasitic infection were at greater risk of being undernourished as compared to pregnant women with no intestinal parasites. Intestinal parasitic infections may affect nutritional status by reducing appetite and dietary intake. It also affects by increasing nutrient losses due to vomiting, diarrhea, poor digestion and absorption. Further, the nutrient demand of parasite itself and intestinal 
bleeding caused by the parasite may contribute to poor nutritional status [42-44].

Major strength of this study was the random selection of the study participants. The major limitation was the cross-sectional nature of its design as we can't establish causal relationships between the independent variables and nutritional status of the pregnant women. Secondly, the study was institution based and the study subjects may not represent the general population. Third, the last date of the menstrual period and/or fundal height with a subsequent urine test, were used to diagnose pregnancy, which may not accurately confirm pregnancy.

\section{Recommendation}

A national level study should be conducted in Ethiopia. The problem must be combated through an implementation of strategies like rural livelihood promotion, socio-economic empowerment of women and expansion of women's education, particularly in rural areas. Nutritional care should be integrated into maternity services. We also suggest sustained nutrition education to enhance good nutritional awareness and practice of pregnant women. Expansion of family planning services will also have affirmative input. Prevention and control of intestinal parasite infection through improving access to safe and adequate water supply; sanitation and hygiene practices should be considered. Screening of pregnant women for intestinal parasitic infections, universal deworming programs, and expansion of prenatal iron-folate supplementation should also be looked for.

\section{Conclusion}

The study findings provide evidence for the public health significance of undernutrition among pregnant in the study area. The important risk factors/ predictors of undernutrition (MUAC $<22 \mathrm{~cm}$ ) were living in rural areas, low educational status, history of too many births, anemia and intestinal parasitic infection.

\section{Abbreviations \\ ANC: Antenatal care; DD: Dietary diversity; DDS: Dietary diversity score; EDHS: Ethiopian Demographic and Health Survey; FANTA: Food and Nutrition Technical Assistance; FAO: Food and Agriculture Organization of the United Nations; MUAC: Mid upper arm circumference; SD: Standard deviation}

\section{Acknowledgements}

We would like to thank the University of Gondar Hospital staffs for their full cooperation and vital assistance during data collection and conducting the laboratory analysis. Special thanks go to entire study subjects for their full participation in the study. We acknowledge University of Gondar and Save the children for funding the study.

\section{Funding}

This study was supported by the University of Gondar and Save the children for data collection material and reagents. However, the they had no role in a decision to publish or preparation of the manuscript.

\section{Availability of data and materials}

The data sets supporting the conclusions of this article are included within the manuscript.

\section{Authors' contributions}

GK participated in study protocol development, data collection, analysis, write-up and drafting of the manuscript. AA, FF, and SE assisted in data collection and reviewing papers. All authors read and approved the final manuscript.

\section{Ethics approval and consent to participate}

Ethical approval was obtained from an ethical review committee of the institute of public health, College of Medicine and Health Sciences, University of Gondar prior to data collection. Permission was taken from the University of Gondar Hospital administrators, and written informed consent was obtained from each study participants prior to participation in the study after the nature of the study was fully explained to the study participants. Participants were told that they had full right to participate or not, and they were also informed that all the data obtained from them would be kept confidential using codes instead of any personal identifiers. Women who had intestinal parasites and anemia were treated accordingly. Those participants identified as undernourished were given nutritional counseling and Ready Use Therapeutic Food (RUTF) in collaboration with the clinicians working in an ART clinic at Gondar hospital.

\section{Consent for publication}

Not applicable.

\section{Competing interests}

We, the authors, have no any competing interests.

\section{Publisher's Note}

Springer Nature remains neutral with regard to jurisdictional claims in published maps and institutional affiliations.

\section{Author details}

${ }^{1}$ Department of Public Health, College of Medicine and Health Science Debre Markos University, Debre Markos, Ethiopia. ${ }^{2}$ Department of Nursing, College of Medicine and Health Science, Debre Markos University, Debre Markos, Ethiopia. ${ }^{3}$ School of Biomedical and Laboratory Sciences, College of Medicine and Health Science, University of Gondar, Gondar, Ethiopia.

Received: 8 February 2018 Accepted: 8 June 2018

Published online: 12 September 2018

\section{References}

1. Piot $P$, Semba R and Bloem M. Nutrition and health in developing countries. Totowa: Springer Science and Business Media; 2008.

2. Adebowale S, Adepoju O, Okareh T. Social epidemiology of adverse nutritional status outcomes among women in Nigeria: NDHS, 2008. Pak J Nutr. 2011;10(9):888-98.

3. Uthman O, Aremu O. Malnutrition among women in sub-Saharan Africa: rural-urban disparity. Rural Remote Health. 2008;8(2):931.

4. Black R, Allen L, Bhutta Z, Caulfield L, Onis M. Maternal and child undernutrition: global and regional exposures and health consequences. Lancet. 2008;371(9608):243-60.

5. Central Statistical Agency (Ethiopia) and ORC Macro. Ethiopia Demographic and Health Survey. Addis Ababa and Calverton: Central Statistical Agency and ORC Macro; 2001.

6. Central Statistical Agency (Ethiopia) and ORC Macro. Ethiopia Demographic and Health Survey. Addis Ababa and Calverton: Central Statistical Agency and ORC Macro; 2006

7. Central Statistical Agency (Ethiopia) and ICF International. Ethiopia Demographic and Health Survey. Addis Ababa and Calverton: Central Statistical Agency (Ethiopia) and ICF International; 2012.

8. Macro International. Ethiopia Atlas of Key Demographic and Health Indicators. Calverton: Macro International; 2008.

9. Landis S, Lokomba V, Ananth C. Impact of maternal malaria and undernutrition on intrauterine growth restriction: a prospective ultrasound study in Democratic Republic of Congo. Epidemiol Infection. 2009;137(02):294-304. 
10. Goyal R, Mudey A, Banginwar A. Intra-uterine growth restriction (IUGR) among teenage and elderly pregnant women in Vidharba region of Maharashtra, India. Int J Cur Bio Med Sci. 2012;2(1):199-202.

11. Blössner M, Onis M, Prüss-Üstün A. Quantifying the health impact at national and local levels. Geneva: WHO; 2005.

12. Teller $\mathrm{C}$ and Yimer $\mathrm{G}$. Levels and determinants of malnutrition in adolescent and adult women in Southern Ethiopia. Ethiop J Health Develop. 2015;14(1):57-66.

13. Girma W, Genebo T. Determinants of nutritional status of women and children in Ethiopia. 2002.

14. Myatt M, Duffield A, Seal A, Pasteur F. The effect of body shape on weightfor-height and mid-upper arm circumference based case definitions of acute malnutrition in Ethiopian children. Ann Human Biol. 2009;36(1):5-20.

15. Garza C, Rasmussen KM. Pregnancy and lactation. In: Garrow JS, James WPT, Ralph A, editors. Human Nutrition and Dietetics. Edinburgh: Churchill Livingstone, London. 2000: p. 437-48.

16. Information and Statistics Office. Information and statistics office. Gondar: University of Gondar Hospital; 2015.

17. Kedir $\mathrm{H}$, Berhane $\mathrm{Y}$, Worku A. Magnitude and determinants of malnutrition among pregnant women in eastern Ethiopia: evidence from rural, community-based setting. Matern Child Nutrit. 2016;12(1):51-63.

18. Swindale A and Bilinsky P. Household dietary diversity score (HDDS) for measurement of household food access: indicator quide. Washington, DC: Food and Nutrition Technical Assistance Project, Academy for Educational Development; 2006

19. Kennedy G, Ballard T, Dop MC. Guidelines for measuring household and individual dietary diversity. Rome: FAO; 2011.

20. Cogill B. Anthropometric indicators measurement guide. 2003.

21. Ververs M, Antierens A, Sackl A. Which anthropometric indicators identify a pregnant woman as acutely malnourished and predict adverse birth outcomes in the humanitarian context? PLOS Currents Disasters; 2013.

22. López L, Calvo E, Poy M. Changes in skinfolds and mid-upper arm circumference during pregnancy in Argentine women. Matern Child Nutrit. 2011;7(3):253-62.

23. Ferro-Luzzi A, James W. Adult malnutrition: simple assessment techniques for use in emergencies. Brit J Nutrit. 1996;75(1):3-10.

24. Woteki CE, and R Earl. Iron deficiency anemia: recommended guidelines for the prevention, detection, and management among US children and women of childbearing age. Washington, D.C.: National Academies Press;1994.

25. Nestel P. Adjusting hemoglobin values in program surveys. Washington, DC: International Nutritional Anemia Consultative Group, International Life Sciences Institute; 2002.

26. Ridley D, Hawgood B. The value of formol-ether concentration of faecal cysts and ova. J Clin Pathol. 1956;9(1):74.

27. Casemore D, Armstrong M, Sands R. Laboratory diagnosis of cryptosporidiosis. J Clin Pathol. 1985;38(12):1337-41.

28. World Health Organization. Bench aids for the diagnosis of intestinal parasites. Geneva: World Health Organization; 1994

29. Kuche D, Singh P, Moges D, Belachew T. Nutritional Status and Associated Factors among Pregnant Women in Wondo Genet District, Southern Ethiopia. JFSE. 2015;5:85-94

30. Regassa N, Stoecker BJ. Contextual risk factors for maternal malnutrition in a food-insecure zone in southern Ethiopia. J Biosoc Sci. 2012;44(5):537-48.

31. Belete $Y$, Negga B, Firehiwot M. Under nutrition and associated factors among adolescent pregnant women in Shashemenne District, West Arsi Zone, Ethiopia: a community-based. J Nutrit Food Sci. 2016;6(1):1-7.

32. Okwu GN, Ukoha Al, Nwachukwu N, Agha NC. Studies on the Predisposing Factors of Protein Energy Malnutrition Among Pregnant Women in a Nigerian Community. Online J Health Allied Scs. 2008;6(3):1-9.

33. Bitew, F.H. and D.S. Telake, Undernutrition among women in Ethiopia: ruralurban disparity. 2010.

34. Winikoff B, Castle M. Defining maternal depletion syndrome. Am J Public Health. 1993;83(7):1052

35. Nucci LB, et al. Nutritional status of pregnant women: prevalence and associated pregnancy outcomes. Rev Saude Publica. 2001;35(6):502-7.

36. Begum S, Sen B. Maternal Health, Child Well-Being and chronic poverty: does Women's agency matter? The Bangladesh Development Studies; 2009. p. 69-93.

37. Abasizadeh S, Hemati Z, Deres F. Prevalence of malnutrition during pregnancy and associated factors in women of Ardal County in 2012-2013. Int J Epidemiol Res. 2016;3(1):19-25.
38. Gedefaw L, Ayele A, Asres Y, Mossie A. Anaemia and associated factors among pregnant women attending antenatal care clinic in Walayita Sodo town, Southern Ethiopia. Ethiop J Health Sci. 2015;25(2):155-64.

39. Okubatsion Tekeste Okube* WM, Odhiambo E, Wakasiaka Sabina MH. Prevalence and factors associated with Anaemia among pregnant women attending antenatal Clinic in the Second and Third Trimesters at Pumwani maternity hospital, Kenya. Open J Obstet Gynecol. 2016;6:16-27.

40. Mondal B, Tripathy $V$, Gupta R. Risk factors of Anemia during pregnancy among the Garo of Meghalaya, India. J Hum Ecol. 2006;14:27-32.

41. Borelli $P$, et al. Reduction of erythroid progenitors in protein-energy malnutrition. Br J Nutr. 2007:97(2):307-14.

42. Arimond M, Daelmans B, Dewey K, Morris S. Maternal and Child Undernutrition 5 Effective international action against undernutrition: why has it proven so difficult and what can be done to accelerate progress? Commentary. Lancet. 2008;371(9612):608-21.

43. Crompton D, et al. Hookworm infection, nutritional status and productivity. In: Hookworm disease-current status and new directions; 1990. p. 231-64.

44. Jardim-Botelho A, et al. Age patterns in undernutrition and helminth infection in a rural area of Brazil: associations with ascariasis and hookworm. Tropical Med Int Health. 2008;13(4):458-67.

\section{Ready to submit your research? Choose BMC and benefit from:}

- fast, convenient online submission

- thorough peer review by experienced researchers in your field

- rapid publication on acceptance

- support for research data, including large and complex data types

- gold Open Access which fosters wider collaboration and increased citations

- maximum visibility for your research: over $100 \mathrm{M}$ website views per year

At BMC, research is always in progress.

Learn more biomedcentral.com/submissions 